\title{
Defining moments
}

Published at www.cmaj.ca on Sept. 28.

$\mathrm{T}$ hree years ago, I was reminiscing with a former classmate, Dr. Bjorn Thomas, about the fact that, as high school students, we really had no idea of what medical school was going to be like. We recalled receiving a 'reality check' from our high school counsellors to the effect that pursuing a career in medicine would be difficult and we should seriously consider another professional path. It still makes me shudder when I think of how I could have had my dreams shattered at such a young age.

Over a barbeque and numerous beers, Dr. Thomas and I cooked up a course to bridge the gap from high school to med school.

Having both been heavily involved in student leadership at high school and university, and having had some background training in medical education, we initially designed and instructed a weekend course that we named MiniMedSchool for students in Vancouver, British Columbia. It consisted of a series of PowerPoint lectures, guest lectures and practical demonstrations, and had one theme: real-world applications.

Our first offering had 25 applicants. We accepted 20 students from grades 10-12, some of whom had completed an overview of human biology and others who had not. One of our younger students once asked, after an introductory lecture, what a nerve was.

The course was based around two clinical scenarios (one taught each day): appendicitis with ensuing methicillinresistant Staphylococcus aureus (MRSA) septicaemia, and an acute coronary syndrome. On the first day, students were instructed about basic anatomy, including bony landmarks, infection control, common pathogens, antibiotics and the concept of resistance. On the second day, the students were taught basic cardiac anatomy and cardiovascular physiology and we dis-

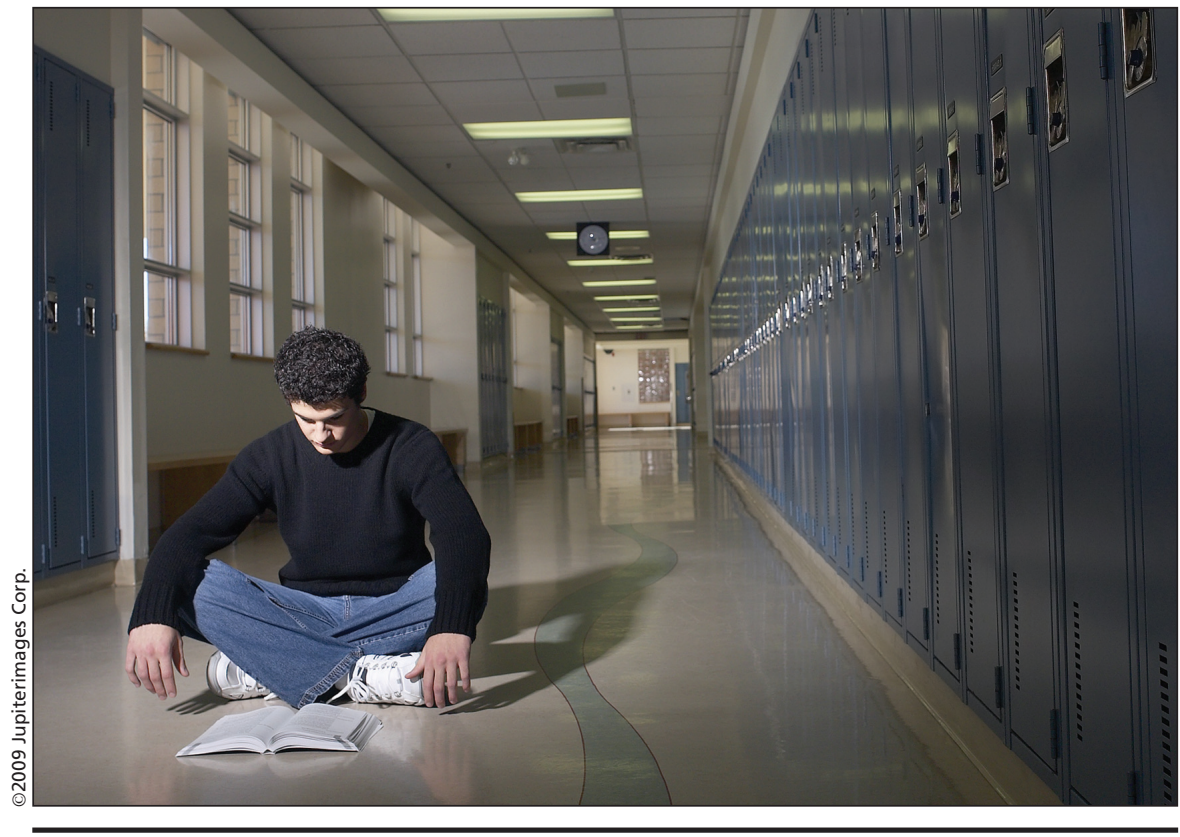

North American doctors should become more involved in instructing high school students about what to expect in medical school, says British physician Alasdair NazeraliMaitland.

cussed some major cardiovascular related diseases, such as myocardial infarction, stroke, angina and hypertension. We concluded with a feedback session and guest lecturers explaining why they studied medicine and sketching their daily duties.

The feedback from that initial offering was outstanding. Younger students encouraged us to change the curriculum so they could attend the following year.

Teaching high school students, as opposed to junior medical students, certainly appealed to us. The former require more charismatic lecturing, as opposed to a pedantic, didactic approach. At MiniMedSchool, we walked around the seminar room, between the rows of desks, delivering real-life analogies and making things understandable for both the brightest and the most distracted students. We perhaps weren't fully prepared for short attention spans and the intermingling of opposite sexes, but it's safe to say that once we appreciated those nuances, the course ran smoothly.

Last year, our course left its infancy and exceeded all projected milestones.
We extended the course to two weeks and doubled the number of tutors to four, while relocating to a wonderful new facility, courtesy of Patrick Dyck at St. George's High School in Vancouver. We began to accept students based on merit and motivation rather than a first-come, first-served basis. We accepted 14 from the Greater Vancouver area, two from Prince George, BC, and four international students (from Ecuador, Guatemala, Hong Kong and Taiwan). We even granted two scholarships for free entry.

Year 2 produced fond memories. We asked the students to think about all of the different things and people that make a hospital function as a whole. There were certainly comedic moments when we asked them to name all the members of a hospital multidisciplinary team. We covered such topics as hospital investigations, common community and hospitalacquired infections, commonly prescribed antibiotics, the basis of a medical history and red flags of a consultation. Prominent local doctors Dr. Brian Day, Dr. Bruce Chang and Dr. Brad Fritz 
offered lectures. We included Case Based Learning on Infections (MRSA sepsis), common conditions in the elderly, as well as some common conditions seen in family practice. We toured the Vancouver General Hospital and had use of its new Resident Simulation Lab, where our students took part in mock cardiac arrest calls, learned how to deal with upper gastrointestinal bleeds, and learned the basis of laparoscopic surgical procedures and neonatal resuscitation.

The second week focused on various medical specialties, learning and practising medical histories, while going through a few more medical school-level cases. We visited a seniors' care facility where students began to learn about the changes in medical practice and the art of preventive medicine. We used cases on osteoporosis, acute coronary syndromes, hypertension and prostate cancer to demonstrate the importance of treating a problem in the community before it presents to a hospital. Among the specialties we touched upon were dermatology (with guest lecturer Dr. Richard Thomas teaching students how to describe lesions and the basis of skin cancers); hematology/oncology (teaching the students the basic principles of blood-based malignancies, a microscope session with some leukemias and a lecture on end-of-life care by Dr. Muni Nazerali); and obstetrics and gynecology (including a lecture by Dr. Amanda Skoll, another on pediatric psychology by Dr. Patrice Dunn, one on homeopathic medicine by Dr. Bal Pawa, and a fourth on the future of medicine by Dr. Larry Goldenberg). We closed out the week with some current cases in medical ethics and an afternoon barbeque.

At the conclusion of the course, I was left pondering whether this was how actors felt after concluding a big theatre production. It was the single most memorable event I have been a part of. Having worked weeks of nights and weekend on calls, I found it to be a different type of stress. I won't compare this to a huge music festival or international conference, but it was definitely my Woodstock.

As I reflect on the course, it seems very important for every student to have a teacher that changes the way he thinks about the world — someone who breaks down barriers, inspires confidence, encourages curiosity and leads by example.

I have been lucky to have had such teachers. I found that the best teachers were happy to go off on tangents and answer problems relating to current events and other student concerns. We adopted that policy at MiniMedSchool, since renamed Med School 101. We had a dedicated area on the whiteboard where students could suggest topics for discussion and we set aside 20 minutes daily to discuss those issues. Students were encouraged to ask questions if they were confused because I knew from personal experience that if one student didn't understand something, chances were that others were equally confused.

Some of the students were absolutely hilarious. Searching for a cheap gag, one student inquired about diarrhea. I think he was absolutely shocked when I started to engage in the topic. We talked about what we thought diarrhea was and what were its causes. Several students had great difficulty understanding that it was increased stool volume/mass rather than increased stool frequency.

Students similarly raised questions about acute coronary syndromes. While researching their case-based learning, they had discovered that there were two acute treatments available: thrombolysis and balloon angioplasty $+/$ - stent insertion. When I suggested there were two correct answers, they were baffled. I spoke about geographical aspects, rescue percutaneous coronary intervention, door-to-needle times as well as the other aspects of coronary artery disease. When we spoke about hypertension, students raised real-life examples. As our case based learning sessions were held in groups of five, students had a chance to teach each other what they had learned from homework assignments. We even had the pleasure of watching shy and timid students become confident and extroverted by week 2 . One such boy was so quick to jump onto a patient's chest and give chest compressions on our simulation day that he forgot to lower the patient's bed and was leaping in the air with each compression!

I was also reminded of the age-old adage: expected the unexpected. Our students, who in the first few days of our course were silent and worked independently, started to form mixed study groups. Maybe this was just an excuse for the boys to go over and talk to the girls, but it sure could have fooled me. By the end of the course, our students had learned procedures that I believe no other high school students, internationally, had learned. To name but a few: they performed interrupted suturing of bovine cardiac muscle, as well as full run throughs of a medical history.

Although my clinical involvement precludes me from teaching during Med School 101's third year, I have the utmost faith in our next generation of teachers: Bjorn Thomas, Justin Chang and Mitch Goldenberg. We are indebted to St. George's for providing us with fantastic facilities, up-to-date equipment and a network of resources. We are particularly indebted to Laurie and Patrick Dyck for letting St. George's handle the planning and the organization of the facilities, so we could focus on teaching and inspiring our students. So successful has the course been that I've even had suggestions for a mini-architecture school and a mini-business school, so if I fancy a break from the sleepless nights of internal medicine, perhaps I have another career waiting in the wings.

Finally, to all North American professors of medicine, I challenge you to involve yourself, as an experiment, with high school students. They are, in many ways, just as intuitive and zealous as postgraduate medical students. With a solid background of biology and a bit of motivation, many of them will be encouraged to pursue their dream of donning white coats and stethoscopes. - Alasdair Nazerali-Maitland MBBS, London, UK

DOI:10.1503/cmaj.109-3063

CMAJ invites contributions to "Dispatch from the medical front," in which physicians and other health care providers offer eyewitness glimpses of medical frontiers, whether defined by location or intervention. Submissions, which must run a maximum 700 words, should be forwarded to: wayne.kondro@cmaj.ca 